\title{
Analysis of width/height ratio and gingival zenith in patients with bilateral agenesis of maxillary lateral incisor
}

\author{
Núbia Inocencya Pavesi Pini', Luciana Manzotti De-Marchi², Bruno Frazão Gribel ${ }^{3}$, \\ Adilson Luiz Ramos ${ }^{4}$, Laurindo Zanco Furquim ${ }^{5}$, Renata Corrêa Pascotto ${ }^{6}$
}

\begin{abstract}
Objective: The purpose of this study was to evaluate the width/length ratio and the gingival zenith (GZ), by means of dental casts and digital caliper, in patients with missing maxillary lateral incisors after treatment. Methods: The sample was composed of 52 subjects divided into 3 groups: BRG ( $n=18)$, patients with bilateral agenesis treated with tooth re-contouring; BIG $(n=10)$ patients with agenesis treated with implants and CG $(n=24)$, control group. The data were analyzed using Shapiro-Wilk, Spearman correlation, Wilcoxon, Kruskal-Wallis, $t$ test and ANOVA tests $(\mathrm{p}<0.05)$. Results: For the width/length ratio of the lateral incisors, BIG presented the lowest mean values (0.72 right and left), when compared with other groups. However, comparison between groups presented statistically significant differences for the right lateral incisor (BIG x CG) and for the canine (BRG x CG). GZ data evaluation showed the greatest difference for BRG (0.5 right and 0.48 left). BIG (0.95 right and 0.98 left) and CG (0.98 right and 0.8 left) presented more similar values, nevertheless, without statistical difference $(\mathrm{p}>0.05)$. GZ data for the right and left sides of the smile were not considered statistically different. Conclusion: Although no statistical difference was found in the comparison between the groups, analysis of the descriptive values showed that group BIG showed the greatest difference in values with regard to width/length ratio. Regarding gingival zenith, BRG showed the greatest difference.
\end{abstract}

Keywords: Dental agenesis. Width/length ratio. Gingival zenith.

Objetivo: o propósito desse estudo foi analisar, por meio de modelos de estudo e paquímetro digital, a proporção largura/altura e o zênite gengival (ZG) em pacientes com agenesia bilateral do incisivo lateral superior após o tratamento. Métodos: a amostra consistiu de 52 voluntários divididos em 3 grupos: GBR ( $n=18)$, pacientes com agenesia bilateral tratados com reanatomizações dentárias; GBI ( $n=10)$, pacientes com agenesia bilateral tratados com implantes; e GC $(n=24)$, grupo controle. Os dados foram avaliados por meio dos testes de Shapiro-Wilk, Wilcoxon, Kruskal-Wallis, teste $t$, ANOVA $(\mathrm{p}<0,05)$ e correlação de Spearman. Resultados: para a proporção largura/altura dos incisivos laterais, o GBI apresentou menores valores (0,72 direito e esquerdo), quando comparado aos demais. Porém, a comparação intergrupos revelou diferenças estatisticamente significativas para o incisivo lateral direito (GBI x GC) e para o canino (GBR x GC). A avaliação das medianas obtidas para o ZG demonstrou que o GBR foi o mais destoante (0,5 direito e 0,48 esquerdo), e que o GBI (0,95 direito e 0,98 esquerdo) e o GC (0,98 direito e 0,8 esquerdo) apresentaram valores semelhantes, sem diferença estatisticamente significativa $(p>0,05)$. Os valores obtidos para os lados direito e esquerdo foram considerados iguais dentro de cada grupo. Conclusão: embora não tenham sido encontradas diferenças estatísticas na comparação entre os grupos, pela análise descritiva dos dados, o GBI foi o grupo que apresentou as medidas mais destoantes dos demais em relação à proporção largura/altura, sendo que, para o zênite gengival, a maior diferença observada foi no GBR.

Palavras-chave: Anodontia. Ortodontia. Implantes dentários.

${ }^{1}$ MSc Student in Dentistry, FOP/UNICAMP.

${ }^{2} \mathrm{MSc}$ in Integrated Dentistry, UEM. Professor, Department of Dentistry at CESUMAR

${ }^{3} \mathrm{MSc}$ in Dentistry PUC/MG. Post-Doctoral Residency, University of Michigan, $\mathrm{PhD}$ Student in Radiology, FOP/Unicamp.

${ }^{4} \mathrm{MSc}$ in Orthodontics, FOB/USP. PhD in Orthodontics, UNESP. Associate Professor of Dentistry, UEM. Professor of Orthodontics, UEM, AMO and CESUMAR.

${ }^{5} \mathrm{PhD}$ in Oral Pathology, FOB/USP. Associate Professor of Dentistry, UEM. Professor of the Specialization Course in Orthodontics, UEM, AMO and CESUMAR.

${ }^{6} \mathrm{MSc}$ and $\mathrm{PhD}$ in Dentistry, USP. Associate Professor of Dentistry, UEM.
How to cite this article: Pini NIP, De-Marchi LM, Gribel BF, Ramos AL, Furquim LZ, Pascotto RC. Analysis of width/height ratio and gingival zenith in patients with bilateral agenesis of maxillary lateral incisor. Dental Press J Orthod. 2012 SeptOct;17(5):87-93.

Submitted: April 9, de 2011 - Revised and accepted: January 28, 2012.

" The authors report no commercial, proprietary or financial interest in the products or companies described in this article.

Contact address: Núbia Pavesi Pini

Rua Madre Cecília, 1560 - bloco F, apto. 43 - Centro

Zip code: 13.400-490 - Piracicaba/SP - Brazil

E-mail: nubiapini01@gmail.com 


\section{INTRODUCTION}

Dental agenesis in the anterior maxillary region compromise the balance and symmetry of the smile, interfering negatively in the patient's interpersonal relationships and self esteem. ${ }^{1,2}$ esthetics of the smile is related to various parameters, and therefore, all professionals involved in the treatment of agenesis of the lateral incisors should aim dentofacial esthetic.

According to contemporary cosmetic literature, an adequate width-length ratio of teeth and the gingival zenith are desirable characteristics for the smile, and may thus be references for esthetic rehabilitation,,$^{3-5}$ such as the treatment required by patients with agenesis. Different authors ${ }^{6-12}$ have studied the above-mentioned esthetic principles, nevertheless, there is little information about how they have been applied in the rehabilitative treatment of patients with agenesis.

Treatment of patients with unilateral or bilateral agenesis of maxillary lateral incisors is an interdisciplinary challenge, requiring correct diagnosis and individual planning in order to restore the long term function and esthetics of the smile. ${ }^{13-15}$ The treatment options generally indicated for these patients are closure of spaces and re-contouring of the canines into lateral incisors or maintaining the spaces for placement of dental implants. ${ }^{16-20}$ Whatever the chosen option may be, procedures are still need to be performed by the orthodontist, either to improve the position of the canine (adequate crown torque and leveling of the gingival margin), or to suit the width of the area of agenesis that will be the implant receptor site to the width of a natural lateral incisor. ${ }^{15,21,22}$

The purpose of the present study was to analyze the width/length ratio and gingival zenith of anterior teeth in patients with agenesis of the maxillary lateral incisor after treatment and discuss the applicability of these esthetic principles and their relationship with the final esthetic appearance of patients with agenesis of the maxillary lateral incisor, treated with space closure and dental re-contouring, or with space opening and implant placement.

\section{MATERIAL AND METHODS}

For this study, 28 patients with bilateral agenesis of the maxillary lateral incisor were selected, and divided into 2 groups according to the treatment performed: BRG $(\mathrm{n}=18)$ - patients with bilateral agenesis treated with orthodontic space closure and dental re-contouring; and BIG ( $\mathrm{n}=10)$ - patients with bilateral agenesis treated with space opening and implant placement. The control group (CG) was composed of 24 patients, selected according to the following criteria: (1) the patient should not have received previous orthodontic or orthopedic treatment; (2) presented no history of facial pain during the previous year; (3) does not use a bruxism plate; (4) presented all teeth in mouth, except the third molar; (5) presented no skeletal discrepancy and (6) has good tooth alignment. The patients in Groups BRG and BIG were evaluated, on an average of 5.03 years and 3.08 years, respectively, after conclusion of interdisciplinary rehabilitative treatment. All the patients were invited to participate in this research and signed a free and informed term of consent approved by the Ethics Committee of the State University of Maringá (Protocol No. 582/2009).

For evaluation of the esthetic principles, study models made of orthodontic plaster (Asfer - Asfer Indústria Química Ltda, São Caetano do Sul) were obtained from impressions of all patients, taken using alginate (Jeltrate Plus - Dentsply, Petrópolis). The width (W) and length (L) of teeth were measured on the models, using a digital caliper (MITUTOYO ${ }^{\circledR}$ - São Paulo/Brazil), and the width/length ratio (W/L) of each tooth was calculated by dividing the width by the height. The gingival zenith (GZ) level of the maxillary lateral incisors (MLI) was evaluated in relation to a line tangent to the GZ of the canines and central incisors, drawn on the study models of the patients (Fig 1). The distance between this line and GZ of the MLI was measured with a digital caliper at $4 \mathrm{X}$ magnification.

For statistical analysis the Software R 2.10.1 was used and the statistical significance level was defined at $5 \%$. For all the analyses, the Shapiro-Wilk test was

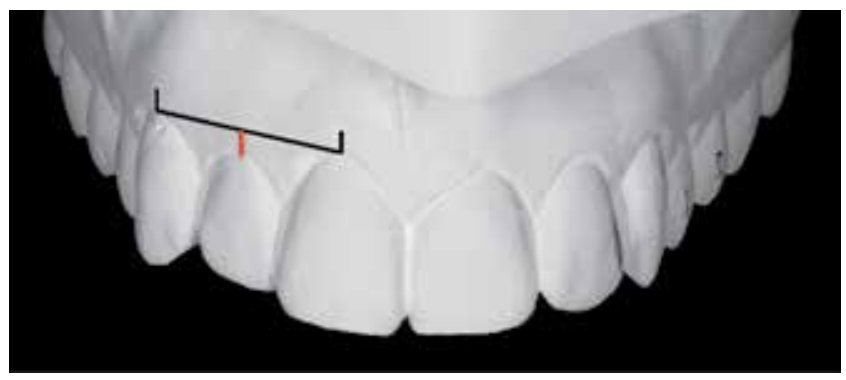

Figure 1 - Analysis of the gingival zenith of the maxillary lateral incisor, obtained from a line tangent to the $G Z$ of the canines and central incisors. 
applied to verify the normality of the data. Spearman's correlation test was applied for the intra-examiner analysis regarding width/length ratio. All the measurements were repeated at two different time intervals by the same observer (interval of 30 days), and abnormal distribution of the sample was verified. To compare the findings of the right and left sides of the smile; (symmetry of the smile), the Wilcoxon test for paired data was applied. For the inter-group comparison the MannWhitney U test was applied. In respect to the gingival

Table 1 - Descriptive Measurements, Normality (SW) and Intra-Observer Correlation ( $R$ ) for analysis of the width/length ratios in the patients treated with re-contouring (BRG), with implants (BIG) and in patients in the Control Group (CG).

\begin{tabular}{|c|c|c|c|c|c|}
\hline Group & Side & Tooth & $\begin{array}{c}\text { Median } \\
\text { (interquartile } \\
\text { rage) }\end{array}$ & sw & $\mathbf{R}$ \\
\hline \multirow{6}{*}{ BRG } & \multirow{3}{*}{ Right } & IC & $\begin{array}{c}0.8186 \\
(0.7776-0.8934)\end{array}$ & 0.3936 & 0.8968 \\
\hline & & IL & $\begin{array}{c}0.8093 \\
(0.7202-0.8911)\end{array}$ & 0.9297 & 0.9216 \\
\hline & & C & $\begin{array}{c}0.7602 \\
(0.7215-0.8879)\end{array}$ & 0.0005 & 0.9236 \\
\hline & \multirow{3}{*}{ Left } & IC & $\begin{array}{c}0.8424 \\
(0.7827-0.9160)\end{array}$ & 0.8785 & 0.9587 \\
\hline & & IL & $\begin{array}{c}0.7813 \\
(0.7419-0.8663)\end{array}$ & 0.9198 & 0.8122 \\
\hline & & C & $\begin{array}{c}0.8409 \\
(0.7531-0.8915)\end{array}$ & 0.7118 & 0.8658 \\
\hline \multirow{6}{*}{ BIG } & \multirow{3}{*}{ Right } & IC & $\begin{array}{c}0.8510 \\
(0.7688-0.9038)\end{array}$ & 0.1738 & 0.9030 \\
\hline & & IL & $\begin{array}{c}0.7299 \\
(0.672-0.7662)\end{array}$ & $<0.0001$ & 0.5030 \\
\hline & & C & $\begin{array}{c}0.7784 \\
(0.7515-0.8075)\end{array}$ & 0.0087 & 0.7818 \\
\hline & \multirow{3}{*}{ Left } & IC & $\begin{array}{c}0.8478 \\
(0.8156-0.9301)\end{array}$ & 0.2900 & 0.9152 \\
\hline & & IL & $\begin{array}{c}0.7299 \\
(0.7125-0.7813)\end{array}$ & 0.2582 & 0.8303 \\
\hline & & C & $\begin{array}{c}0.7574 \\
(0.7029-0.8184)\end{array}$ & 0.8632 & 0.9030 \\
\hline \multirow{6}{*}{ CG } & \multirow{3}{*}{ Right } & IC & $\begin{array}{c}0.8524 \\
(0.8073-0.9234)\end{array}$ & 0.0017 & 0.8585 \\
\hline & & IL & $\begin{array}{c}0.7740 \\
(0.7740-0.8438)\end{array}$ & 0.0028 & 0.8192 \\
\hline & & C & $\begin{array}{c}0.8817 \\
(0.8244-0.9287)\end{array}$ & 0.6642 & 0.7646 \\
\hline & \multirow{3}{*}{ Left } & IC & $\begin{array}{c}0.8488 \\
(0.8011-0.9109)\end{array}$ & 0.0275 & 0.5808 \\
\hline & & IL & $\begin{array}{c}0.7619 \\
(0.7251-0.8299)\end{array}$ & 0.0002 & 0.6392 \\
\hline & & C & $\begin{array}{c}0.8439 \\
(0.7847-0.8664)\end{array}$ & 0.2357 & 0.8715 \\
\hline
\end{tabular}

zenith, observer calibration was performed by means of three analyses, with an interval of 7 days between them, of a sample of 5 randomly selected patients. The three observations were compared by the Spearman Correlation test again. This test was chosen because normal distribution of the data was not verified. To measure equality of the GZ on the right and left sides of the smile, the paired $t$ test was applied, and for inter-group comparison, the ANOVA Test.

\section{RESULTS}

With regard to the width/length ratio, the values of the lateral incisors of BRG (0.81 right/0.84 left) were found to be the closest to those of CG (0.85 right/0.84 left). The analysis of normality by the Shapiro-Wilk (SW) test showed abnormal distribution of the data, which justified the use of parametric tests (Table 1). The comparison made between the two observations showed no statistically significant differences, demonstrating that the examiner was duly calibrated for the measurements (Table 1). Figure 2 demonstrated that although the width/length ratio presented very similar values for the three groups, the medians of each dimension, in particular width and length, revealed that proportionally, the canines transformed into lateral incisors in BRG were larger than the lateral incisors in CG.

Analysis of the symmetry of the smile using the data obtained for the right and left sides of the width/height ratio, revealed that there was no statistically significant difference among the groups ( $>$ > 0.05) (Table 2).

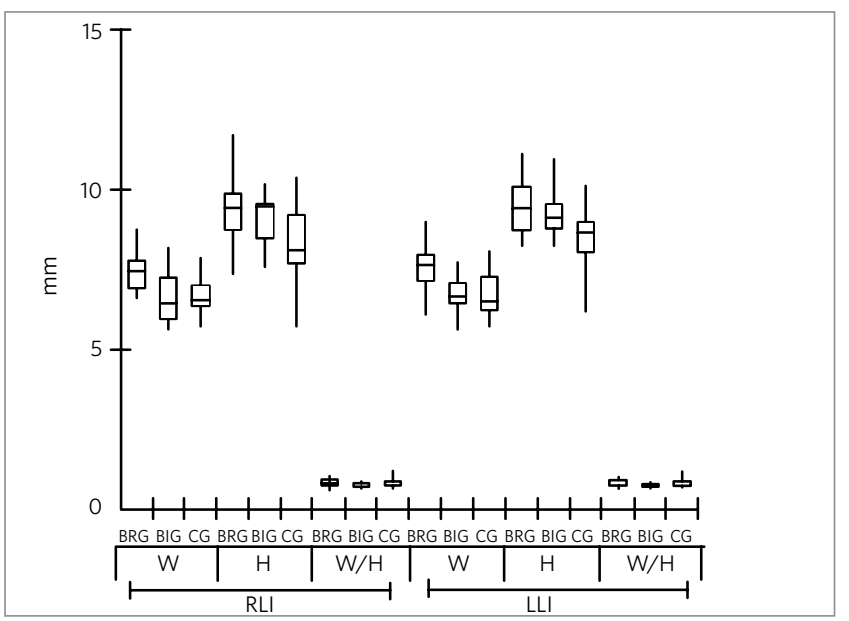

Figure 2 - Analysis of the width $(W)$, height $(H)$ and the width/height ratio $(\mathrm{W} / \mathrm{H})$ for the right and left lateral incisors (LI) of do BRG (Group with bilateral agenesis treated with re-contouring), BIG (Group with bilateral agenesis treated with implants) and CG (Control Group). 
According the Kruskal-Wallis test, the intergroup comparison revealed statistically significant differences only between BIG and CG for the right lateral incisor; and between $\mathrm{BRG}$ and $\mathrm{CG}$, for the right canine (Table 3 ).

For evaluation of the gingival zenith, the three analyses performed by the same observer could not be considered statistically different, according to the Spearman Correlation test (coefficient R > 0.9). Evaluation of the medians obtained for $\mathrm{GZ}$ demonstrated that BRG was the group that differed most from the others, and that the values shown between BIG and CG were the most similar (Table 4). According to the $t$ test, the data

Table 2 - Analysis of the symmetry of data of each group for the right and left sides by the Wilcoxon Test. (BRG - patients treated with recontouring; BIG - patients treated with implants; CG - Control Group).

\begin{tabular}{ccc} 
Group & Tooth & p value \\
\hline \multirow{2}{*}{ BRG } & $\mathrm{Cl}$ & 0.286 \\
\cline { 2 - 3 } & $\mathrm{LI}$ & 0.6165 \\
\cline { 2 - 3 } & $\mathrm{C}$ & 0.4204 \\
& $\mathrm{IC}$ & 0.2411 \\
\cline { 2 - 3 } & $\mathrm{LI}$ & 0.7989 \\
\hline \multirow{2}{*}{ CG } & $\mathrm{C}$ & 0.0593 \\
& $\mathrm{IC}$ & 0.9678 \\
\hline & $\mathrm{LI}$ & 0.326 \\
\hline & $\mathrm{C}$ & 0.0004 \\
\hline
\end{tabular}

obtained for the gingival zenith for the right and left sides of the smile could be considered not statistically different (Table 4). In the inter-group comparison by the ANOVA test, no statistically significant difference was shown among the groups (Table 4).

\section{DISCUSSION}

This is a pioneer study in contemplating analysis of esthetic principles, such as the width/length ratio and gingival zenith, in a sample composed of patients with agenesis of the maxillary lateral incisor. According to the literature, the treatment modalities applicable to patients with agenesis of the maxillary lateral incisor have been widely studied from a functional point of view. ${ }^{41-45}$ However, there is a lack of studies that relate esthetic principles to the final outcome of treatments applicable to these patients. Quantitative and qualitative evaluation of the width/length ratio of teeth and position of the lateral incisor zenith in relation to formation of the gingival triangle has not yet been a widely performed analysis in the literature. Conduct this study in patients with agenesis of the maxillary lateral incisor after treatment with implants or re-contouring, in comparison with a control group, provided an opportunity to evaluate this esthetic principle and its behavior in cases of multidisciplinary esthetic rehabilitation. Descriptive analysis of the measurements of width/length ratio revealed important peculiarities in each group with regard to this esthetic

Table 3 - Inter-group comparison for the width/length data by the Kruskal-Wallis test $(P<0.05)$.

\begin{tabular}{cccccc} 
Groups & RCI & RLI & RC & LCI & LLI \\
BRGxBIG & 0.6661 & 0.0615 & 0.7372 & 0.5651 & 0.551 \\
BRGxCG & 0.1151 & 0.9411 & 0.0193 & 0.6052 & 0.5383 \\
BIGxCG & 0.401 & 0.0236 & 0.06 & 0.9128 & 0.1344 \\
\hline
\end{tabular}

(BRG - patients treated with re-contouring; BIG - patients treated with implants; CG - Control Group).

Table 4 - Medians and quartiles, comparison for the data of right and left sides of the smile by the $t$ test and inter-group comparison for the gingival zenith data for each group.

\begin{tabular}{|c|c|c|c|c|c|c|c|}
\hline Tooth & Data & BRG & BIG & CG & BRG $x$ BIG & BRG $x$ CG & BIG $\times$ CG \\
\hline \multirow{2}{*}{ ILD } & Median & 0.58 & 0.95 & 0.98 & \multirow{2}{*}{0.8884} & \multirow{2}{*}{0.9467} & \multirow{2}{*}{0.0956} \\
\hline & (Quartil) & $(-1.72-2.09)$ & $(0-1.87)$ & $(0-1.9)$ & & & \\
\hline \multirow{2}{*}{ ILE } & Median & 0.48 & 0.98 & 0.8 & \multirow{2}{*}{0.7478} & \multirow{2}{*}{0.0942} & \multirow{2}{*}{0.7092} \\
\hline & (Quartil) & $(-0.55-1.96)$ & $(0-1.68)$ & $(-0.56-2.08)$ & & & \\
\hline \multicolumn{2}{|c|}{$t$ test ( $p$ value) } & 0.95 & 0.95 & 0.36 & & & \\
\hline
\end{tabular}

(BRG - patients treated with re-contouring; BIG - patients treated with implants; CG - Control Group). 
principle. The values (Table 1) of the width/length ratio of the incisors in all the groups were in agreement with the values found by Hasanreisoglu et al, ${ }^{9}$ and Sterret et al. ${ }^{11}$ The canine measurements were shown to be within the values found by Sterret et al, ${ }^{11}$ ranging between 75-84\%, except for the width/ length ratio value found for the right canine in the control group. Regarding the lateral incisors, BRG and CG presented values comparable with those related by Hasanreisoglu et al, ${ }^{9}$ and Gillen et al, ${ }^{12}$ ranging between $79-82 \%$. BIG presented width/length ratio values of approximately $72 \%$ for lateral incisors, which have not yet been related by any author.

The fact that the values found for lateral incisors in BRG were higher than those found in BIG demonstrated that for BRG group, the width and length measurements of the teeth presented values that were closer to one another (Fig 2), which resulted in a high quotient, when the width was divided by the length. Actually, In BRG, it is the transformed canine that is being analyzed, and in BIG, orthodontic treatment is normally necessary before implant therapy to adjust the width of the receptor area to that of a natural lateral incisor. Therefore, this data can be explained by the anatomic differences existent between the canine and lateral incisor, as canines are generally larger than lateral incisors. ${ }^{9-12,23,24}$

The values found for the width/length ratio in CG were higher than those found in the other groups. However, when comparing the medians of each dimension of this tooth in particular, it could be verified that BRG presented higher values for width and length, this can be explained by the fact that a re-contoured canine from BRG was being compared with a natural lateral incisor from CG. In addition, Figure 2 demonstrates that although the medians found for BIG were lower than those found for CG, both groups presented width dimension values that were very close, and greatly divergent values for length. This may be a result of limitations of the implant technique, because although the width of the receptor area may be adjusted to that of a natural lateral incisor, the height cannot always be re-established proportionally to the width. Such limitations are related to the height of the bone crest and thickness of keratinized tissue around the implant, which vary according to the type of platform or connection used, the relationship of the implant with the adjacent teeth, level of location of the implant/connector junction in relation to the bone crest, and the gingival biotype. ${ }^{24,25,26}$

When comparing the data obtained for the width/ length ratio of teeth on the right and left sides of the smile, for the two variables, all the patients in all the groups may be considered symmetrical. This comparison was necessary to find out whether the clinicians were taking into account the re-establishment of symmetry and balance of the smile in the rehabilitation of cases of agenesis. This symmetry is guaranteed by orthodontics, either in the distribution of spaces for re-contouring of the anterior segment of the smile, as in the case of patients in BRG, or in adjusting the receptor area of the implant, in the case of BIG. In spite of the absence of statistically significant differences in this comparison, variations with regard to the medians of the width/length ratio were found in a large portion of the sample. It could be inferred that this was as a result of small alterations in the dimensions of some of the anterior teeth, which are generally not noticed. Kokich et $\mathrm{al}^{27,28}$ reported that small alterations of up to $2 \mathrm{~mm}$ in width of the lateral incisor were not perceived by orthodontists, general clinicians and laypersons, which justifies the results observed in the present study.

In the inter-group comparison, for the width/ length ratio, statistically significant difference between BIG and CG was found only for the right lateral incisor $(\mathrm{p}=0.0236)$, with the justification that in BIG, the dentures showed elongated lengths when compared with CG. Another statistical difference found was for the right canine in the comparison between BRG and CG ( $p=0.0193)$, due to the fact that between these two groups, the premolars that substituted the canines in BRG were being compared with the canines in CG.

For analysis of the gingival zenith, the GZ of teeth were marked according to the pattern established in the literature. ${ }^{4,6,7,29}$ For central incisors and canines, GZ is the most apical point of the gingival outline, generally located distally to the long axis of the tooth, whereas for the lateral incisors, in the majority of cases, this point is coincident with the long axis of the tooth.

Although no statistically differences were found in the comparison between BIG and CG ( $p=0.0956)$, 
analysis of the medians demonstrated differences in the position of the gingival zenith between the 3 groups: Re-contoured canines of the patients in BRG, the implants of the patients in BIG and the natural lateral incisor of the patients in CG. The presence of lower values in BRG demonstrated that in this group, the mesialization of the canines promoted the formation of this triangle in an opposite manner in the majority of the patients; that is to say, the zeniths of the lateral incisors in this group were predominantly found to be coincident or above the reference line of analysis. This is explained by the difference between the GZ of canines and premolars, in relation to the teeth they are replacing; in other words, the lateral incisors and canines respectively. Although these differences can be minimized with orthodontic space closure treatment before dental re-contouring, the discrepancy between the measurements of the right and left lateral incisors (Table 3) demonstrated that in the majority of the cases, this is not always possible, in disagreement with the pattern proposed in the literature., ${ }^{4,529,30}$ However, BRG was the group that presented the most similar values between RLI and LLI; that is to say, presented a greater trend towards symmetry in relation to GZ, ratifying the importance of orthodontic therapy associated with restorative therapy in the treatment with space closure and dental re-contouring. Although BIG was not shown to be as symmetrical as BRG, when compared with $\mathrm{CG}$, the proximity between the values found for right and left GZ demonstrated that symmetry is also of concern to orthodontists in the treatment of opening or maintaining space for the placement of dental implants in patients with agenesis of the maxillary lateral incisors.

It is known that in addition to the variables under study, the width/length ratio and gingival zenith, many others that are difficult to quantify deserve attention when analyzing a peculiar sample, such as patients with agenesis of the maxillary lateral incisor. Clinicians must take other clinical parameters into consideration, both in planning and in the final stage of their clinical cases. The literature relates that both treatment options have their peculiarities. Re-contouring of the lateral incisors into canines is considered advantageous because it leads to minimal or no clinical and radiographic alteration over the course of time, ${ }^{15,22}$ less dental plaque accumulation, gingival inflammation and fewer periodontal pockets. ${ }^{14,16,19}$ In addition it is considered an easily reversible procedure for color adjustment and adaptation of the restoration when necessary, when compared with prosthetic treatments. The disadvantage generally pointed out for this treatment is the lack of occlusion mutually protected by the canine. ${ }^{16} \mathrm{Nev}-$ ertheless, the literature is emphatic about not correlating this fact with possible temporomandibular dysfunction, and consider that the premolar may be considered a suitable substitute for the canine, from a functional point of view..$^{14,18,19,20,31}$ dental implants, are also a treatment option in the absence of lateral incisors, substituting adhesive dentures and fixed partial or removable dentures. This alternative has been considered conservative due to the preservation of permanent teeth adjacent to the prosthetic space; ${ }^{31}$ and shorter orthodontic treatment time required. ${ }^{32}$ However, the quantity and quality of bone, with consequent risk of infra-occlusion, and bone maturation of the individual are factors that interfere in the longitudinal results of dental implants. ${ }^{33}$

Whatever may be the treatment option chosen, Orthodontics is essential in the multidisciplinary team for the treatment of patients with agenesis of the maxillary lateral incisor, as these procedures are necessary to restore the shape and proportionality of the smile and contribute to both the functional and esthetic re-establishment of the patient. ${ }^{21,22}$

The limitations and differences in the results between this study and others may be attributed to various factors ranging from variations in methods; such as using models or photographs, rulers, compasses or caliper, and size and ethnicity of the sample. It is worth pointing out that patients with agenesis of the maxillary lateral incisors constitute a peculiar sample, and difficult to be available. Finally, the results of this study and the literary findings indicate the need for further research about the application of the principles of esthetic proportions in the treatment of patients with agenesis of the maxillary lateral incisor. It is necessary to increase these analysis, with a larger number of patients to establish the differences among groups and patterns, and with control of these patients, in order to enable evaluation of the long term esthetic results of the treatments. 


\section{CONCLUSIONS}

According to the results obtained in the evaluation of the three groups, it could be concluded that:

» There was no statistically significant difference in the width/length ratio among patients with bilateral agenesis of the lateral incisors treated with re-contouring (BRG) or implants (BIG) and the control group (CG), however, when comparing the medians found for the lateral incisors, BIG presented lower values than BRG and CG;

» Regarding the gingival zenith, BRG was the group that differed most from the others, presenting negative values, suggesting that replacing lateral incisors and canines by re-contoured canines and premolars respectively, does not contemplate the formation of the gingival triangle, as esthetically recommended.

\section{REFERENCES}

1. Araújo EA, Oliveira DS, Araújo MT. Diagnostic protocol in cases of congenitally missing maxillary lateral incisors. World J Orthod. 2006;7:376-388.

2. Cunningham SJ, O'Brien C. Quality of life and orthodontics. Seminars in Orthod. 2006;13(2):96-103

3. Fradeane M. Evaluation of dentolalabial parameters as part of a comprehensive esthetic analysis. Eur J Esthet Dent. 2006;1(1):62-69.

4. Magne P. Bonded porcelain restorations in the anterior dentition: a biomimetic approach. Chicago (IL): Quintessence; 2002.

5. Goldstein RE. Esthetics in Dentistry. 2nd Ed. London: Hamilton; 1998. p. 11-49.

6. Chu SJ, Tan JHP, Stappert CFJ, Tarnow DP. Gingival zenith positions and levels of the maxillary anterior dentition. J Esthet Restor Dent. 2009;21(2):113-120.

7. Mattos CML, Santana RB. A quantitative evaluation of the spatial displacement of the gingival zenith in the maxillary anterior dentition. J Periodontol. 2008;79(10):1880-5.

8. Zlataric DK, Kristek E, Celebic A. Analysis of width/length ratios of normal clinical crowns of the maxillary anterior dentition: Correlation between dental proportions and facial measurements. Int J Prosthod. 2007;20:313-5.

9. Hasanreisoglu U, Berskun S, Aras K, Arslan I. An analysis of maxillary anterior teeth: Facial and dental proportions. J Prosthet Dent. 2005;94:530-8.

10. Magne P; Galluci GO. Belser UC. Anatomic crown width/length ratios of unworn and worn teeth in white subjects. J Prosthet Dent. 2003;89:453-61.

11. Sterret JD, Oliver T, Robinson F, Fortson W, Knaak B, Russel CM. Width/length ratios of normal clinical crowns of the maxillary anterior dentition in man. J ClinPeriodontol. 1999:26:153-7.

12. Gillen RJ, Schwartz RS, Hilton TJ, Evans DB. An analysis of selected normative tooth proportions. Int J Prosthodont. 1994;7:410-7.

13. Sabri R. Management of missing lateral incisors. J Am Dent Assoc. 1999;130:80-4

14. Turpin LT. Treatment of missing lateral incisors. Am J Orthod Dentofacial Orthop. 2004 Feb;125(2):129.

15. Rosa M, Zachirisson BU. Integrating esthetic dentistry and space closure in patients with missing maxillary lateral incisors. J Clin Orthod. 2001;35(4):221-33.

16. Robertsson S, Mohlin B. The congenitally missing upper lateral incisor. A retrospective study of orthodontic space closure versus restorative treatment. Eur J Orthod. 2005:22:697-710.

17. Araújo EA, Oliveira DS, Araújo MT. Diagnostic protocol in cases of congenitally missing maxillary lateral incisors. World J Orthod. 2006;7: 376-88.

18. Senty EL. The maxillary cuspid and missing lateral incisors: Esthetics and occlusion. Angle Orthod. 1976;46:365-71.
19. Nordquist GC, McNeill RW. Orthodontic vs. restorative treatment of the congenitally absent lateral incisor - long term periodontal and occlusal evaluation. J Period. 1975;46:139-43

20. Tuverson DL. Orthodontic treatment using canines in place of missing lateral incisors. Am J Orthod Dentof Orthop. 1970;58:109-27.

21. Sunguino R, Furquim LZ. Uma abordagem estética e funcional do tratamento ortodôntico em pacientes com agenesias de incisivos laterais superiores. $R$ Dental Press Ortodont Ortop Facial. 2003;8(6):119-57.

22. Zachrisson BU. Improving the esthetic outcome of canine substitution for missing maxillary lateral incisors. World J Orthod. 2007;8:72-9.

23. Ker AJ, Chan R, Fields HW, Beck M, Rosentiel S. Esthetics and smile characteristics from the layperson's perspective: A computer-based survey study. J Am Dent Assoc. 2008;139:1318-27.

24. Cappiello M, Luongo R, Di Lorio R, Bugea C, Cocchetto R, Celltti R. Evaluation of peri-implant bone loss around platform-switched implants. Int J Period Resto Dent. 2008;28(4):346-55

25. Guirado JLC, Yuguero MRS, Zamora GP, Barrio EM. Immediate provisionalization on a new implant design for esthetic restoration and preserving crestal bone. Impl Dent. 2007;16(2):155-64.

26. Hermann $F$, Lerner $H$, Palti A. Factors influencing the preservation of the periimplant marginal bone. Imp Dent 2007;16(2):165-175

27. Kokich VO, Kokich VG, Kiyak HA. Perceptions of dental professionals and laypersons to altered dental esthetics: Asymmetric and symmetric situations. Am J Orthod Dentofac Orthop. 2006:2:141-51.

28. Kokich Jr VO, Kiyak HA, Shapiro PA. Comparing the perception of dentists and lay people to altered dental esthetics. J Esthet Dent. 1999;6:311-24.

29. Sarver DM. Principles of cosmetic dentistry in orthodontics. Part 1: Shape and proportionality of anterior teeth. Am J Orthod Dentofacial Orthop. 2004;126:749-53.

30. Davis NC. Smile design. Dent Clin N Am. 2007;52:299-318.

31. Richardson G, Russel KA. Congenitally missing maxillary lateral incisors and orthodontic treatment considerations for the single-tooth implant. J Can Dent Assoc. 2001;67:25-28.

32. Thilander B, Ödman J, Lekholm U. Orthodontic aspects of the use of oral implants in adolescents: a 10 year follow-up study. Eur J Orthod. 2001:23(6):715-31

33. Kinzer GA, Kokich Jr VO. Managing Congenitally Missing Lateral Incisors Part III: single-tooth implants. J Esthet Rest Dent. 2005;17:202-10. 